\title{
Article \\ Hybrid Optimization Method for Correcting Synchronization Errors in Tapping Center Machines
}

\author{
Ping-Yueh Chang ${ }^{1}$, Po-Yuan Yang ${ }^{2}$, Shao-Hsien Chen ${ }^{3}$ and Jyh-Horng Chou ${ }^{1,4, *(1)}$ \\ 1 Department of Electrical Engineering, National Kaohsiung University of Science and Technology, 415, \\ Chien-Kung Rd., Kaohsiung 807, Taiwan; 1105404103@nkust.edu.tw \\ 2 Department of Information Engineering and Computer Science, Feng Chia University, 100, Wenhwa Rd., \\ Taichung 407, Taiwan; pyang@fcu.edu.tw \\ 3 The Graduate Institute of Precision Manufacturing, National Chin-Yi University of Technology, 57, Sec. 2, \\ Zhongshan Rd., Taichung 411, Taiwan; e6036@ncut.edu.tw \\ 4 Department of Mechanical Engineering, National Chung-Hsing University, 145 Xing-Da Road, \\ Taichung 402, Taiwan \\ * Correspondence: choujh@nkust.edu.tw
}

Citation: Chang, P.-Y.; Yang, P.-Y.; Chen, S.-H.; Chou, J.-H. Hybrid Optimization Method for Correcting Synchronization Errors in Tapping Center Machines. Appl. Sci. 2021, 11, 3441. https://doi.org/10.3390/ app11083441

Academic Editors: Mark Jackson and Rui Araújo

Received: 11 March 2021

Accepted: 8 April 2021

Published: 12 April 2021

Publisher's Note: MDPI stays neutral with regard to jurisdictional claims in published maps and institutional affiliations.

Copyright: () 2021 by the authors. Licensee MDPI, Basel, Switzerland. This article is an open access article distributed under the terms and conditions of the Creative Commons Attribution (CC BY) license (https:// creativecommons.org/licenses/by/ $4.0 /)$.

\begin{abstract}
A hybrid method is proposed for optimizing rigid tapping parameters and reducing synchronization errors in Computer Numerical Control (CNC) machines. The proposed method integrates uniform design (UD), regression analysis, Taguchi method, and fractional-order particle swarm optimizer (FPSO) to optimize rigid tapping parameters. Rigid tapping parameters were laid out in a 28-level uniform layout for the experiments in this study. Since the UD method provided a layout with uniform dispersion in the experimental space, the UD method's uniform layout provided iconic experimental points. Next, the 28-level uniform layout results and regression analysis results were used to obtain significant parameters and a regression function. To obtain the parameter values from the regression function, FPSO was selected because its diversity and algorithmic effectiveness are enhanced compared with PSO. The experimental results indicated that the proposed method could obtain suitable parameter values. The best parameter combination in FPSO yielded the best results in comparisons of the non-systematic method. Next, the best parameter combination was used to optimize actual CNC machining tools during the factory commissioning process. From the commissioning process perspective, the proposed method rapidly and accurately minimizes synchronization error from 23 pulses to 18 pulses and processing time from $20.8 \mathrm{~s}$ to $20 \mathrm{~s}$. In conclusion, the proposed method reduced the time needed to tune factory parameters for CNC machining tools and increased machining precision and decreased synchronization errors.
\end{abstract}

Keywords: tapping center machine; uniform design; Taguchi method; fractional-order particle swarm optimizer

\section{Introduction}

Manufacturing internally threaded mechanical parts, particularly parts with numerous threads, requires high machining precision. Fabrication of threads using high-precision molds is usually the final step in the manufacturing process. Therefore, manufacturers require a reliable method of maintaining high quality in machining internal threads, especially in mass-produced mechanical components with internal threads. Tapping accuracy largely depends on whether the movement of the feed of the tapping axis is well synchronized with the rotation of the spindle during the tapping cycle. The observed index of the tapping axis feed to spindle rotation is the synchronization error. Therefore, to obtain a high-precision internal thread by rigid tapping, the goal is to minimize synchronization error.

For servo parameter commissioning, Lee et al. [1] proposed an iterative measurement and contour performance simulation. Servo parameters were adjusted to reduce contour error, and the Kreuz-Gitter-Meßsystem (KGM) method was used to verify the contour's 
accuracy. Yeh et al. [2] proposed "learning automata," an automatic parameter adjustment method for improving parameter convergence and improving efficiency in adjusting control parameters. To optimize the synchronous motion between the spindle and the tap-ping axis, Yeh et al. [3] proposed several linear and nonlinear control design techniques for improving control performance and synchronization, including (1) Cross-coupling control, (2) Nonlinear friction compensation, and (3) Interference observation. Servo gain was optimized by the command control method. The authors achieved synchronization accuracy within 10 ums at a spindle speed of $6000 \mathrm{rpm}$ by applying these techniques. Lu et al. [4] used a fuzzy adaptive proportional-integral-derivative (PID) controller to control Computer Numerical Control (CNC) machine tools used in rigid tapping. The proposed control method can be performed without establishing a controlled object, and the online PID controllable parameters are automatically adjusted by the fuzzy inference method. In another study, Ishizaki et al. [5] proposed a cross-coupled controller for accurately synchronizing the motion of a servo system driven by dual motors. The proposed cross-coupled controller compensates for differential positioning errors between dual servo drives by modifying reference positions and speed commands. Biris et al. [6] performed experiments to compare the effectiveness of eliminating positioning and contour errors. The authors also proposed an adjustment method based on a mathematical model and evaluated its performance in reducing positioning and contour errors in CNC machine tools. Chen et al. [7] proposed an iterative learning control (ILC) algorithm for reducing synchronization error in rigid tapping.

In recent years, additive manufacturing ( $\mathrm{AM}$ ) technology has been proposed to be suitable for manufacturing critical components. Additive manufacturing is completely different from traditional subtractive processing. In contrast, additive manufacturing uses polymer, metal, or ceramic material spray stacking to construct a 3D shapes method that can quickly and flexibly produce a small number of diverse products, significantly reducing the time from the design stage to mass production of the products and considerably improving the utilization rate of materials [8-12]. At present, additive manufacturing can be used to produce energy, aerospace, or biomedical parts, providing high-strength and lightweight products. The machine tools manufacturer MAZAK's hybrid multi-objective machine tool type can perform laser additive manufacturing and 5-axis machining processes on machine tools, demonstrating the possibilities and characteristics of future advanced techniques [13].

The learning control modifies the $z$-axis and the spindle commands to optimize synchronicity between $z$-axis output responses and the spindle. Their experiments revealed that 10 runs of the ILC algorithm reduced synchronization error from $0.26 \mathrm{~mm}$ to $2.6 \times 10^{-13}$. That is, the use of ILC learning control can substantially reduce synchronization error. Chen et al. [14] proposed intelligent computer-aided process planning (i-CAPP). When the machining process's complexity increases, i-CAPP's Integration intelligence function works together with the domain expert's procedure. Ma et al. [15] accord the coupling between the radial and axial vibrations and the dynamic cutting forces modeled along the tapping path. The radial and axial chatter stability is separately predicted in the frequency domain for the tapping process's stability.

In the past, when the machining process was executed in the factory, the teeth or the tapping tools occasionally broke when the tapping speed was different. Usually, it was necessary to wait for the equipment manufacturer to inspect the equipment to obtain the best parameters. The current study developed a novel method of adjusting rigid tapping electrical control parameters and explored the effects of the adjusted parameters on thread quality obtained by tapping in internally threaded parts. The proposed method combines uniform design (UD) [16-19], regression analysis [20-23], fractional-order particle swarm optimizer (FPSO) [24-28], and the Taguchi method [29-36] to analyze the effects of rigid tapping parameters on thread quality and to determine the key parameters and the optimal parameter values. Application of the proposed method in an actual factory process verified its effectiveness for improving thread tapping quality. Through the method provided in this article, the processing industry can get the minimum error parameter combination at 
different tapping speeds through experiments to avoid breaking the tool when rigid tapping is performed at the end of the processing process and causing damage to the workpiece.

This paper is organized as follows. The problem considered in this study is briefly described in Section 2. Section 3 briefly discusses relevant methods, including UD, regression analysis, FPSO, and the Taguchi method. Section 4 presents and discusses the experimental and simulation results. Finally, Section 5 concludes the study.

\section{Problem Description}

Machining internal threads is an essential process in mechanical parts manufacturing in various industries. For example, numerous internally threaded holes are required to manufacture printed circuit boards (PCBs) in the computer, communications, and consumer-electronics (3C) electronics industry and manufacture mobile phone cases in the mold industry. Holes are typically threaded in a late stage of the manufacturing process. Poorly threaded holes can severely diminish the manufactured part's quality and performance; therefore, manufacturers require a fast and reliable method for tapping internally threaded holes.

Tapping can be classified as floating or rigid. Each method uses a different tool clamping device, so each method has different synchronization requirements for the spindle and the tapping axis. Floating tapping was developed to solve the problem of synchronization between the spindle and the tapping axis. In floating tapping, the tap-ping tool is clamped in an elastic chuck. The advantage of floating tapping is that tapping can be achieved without complex control theory. The disadvantage, however, is that an excessively high tapping speed causes severe vibration resulting in imprecise tapping and/or disordered or broken teeth. In rigid tapping, a tap collet is typically used to clamp the tapping tool, which provides more precise teeth and enables a more efficient tapping speed than floating tapping. Rigid tapping is also much faster than floating tap-ping. However, synchronization between the spindle and the tapping axis must be exact. Even a slight difference can cause a breakage of the tool. Therefore, accurate synchronization of the spindle and tapping axis is essential. Most research in rigid tap-ping control has focused on minimizing the synchronization error between the tapping axis movement and the spindle to obtain internal threads with high quality and accuracy.

To obtain the required screw pitch specifications in a rigid tapping process, the tapping axis and the spindle must be adjusted to meet the required combination of spindle speed and feed rate of the tapping axis. The relationships can be formulated as in Equation (1)

$$
P=F / S
$$

where $P$ is the thread pitch (unit: $\mathrm{mm}$ ), $F$ is the feed rate of the tapping axis (unit: $\mathrm{mm} / \mathrm{min}$ ), and $S$ is the spindle speed (RPM).

In a rigid tapping procedure, the spindle speed and tapping axis feed rate must maintain a certain proportional relationship according to the required pitch specifications. Because pitch $P$ depends on the scale of spindle speed and feed rate of the feed axis, if spindle speed and feed rate of feed axis do not match, it causes synchronization error which is too large and pitch $P$, not precision. Therefore, the controller has a command-type compensation architecture, and the controller simultaneously commands the spindle and the tapping axis and compensates for positioning errors.

Additionally, the FANUC 31iMA controller used in this experiment is that the control method in which the tapping axis follows the spindle identifies synchronization errors between the spindle and the tapping axis. Figure 1 shows that synchronization error is an essential indicator in rigid tapping because it affects internal threads' shape and precision. 


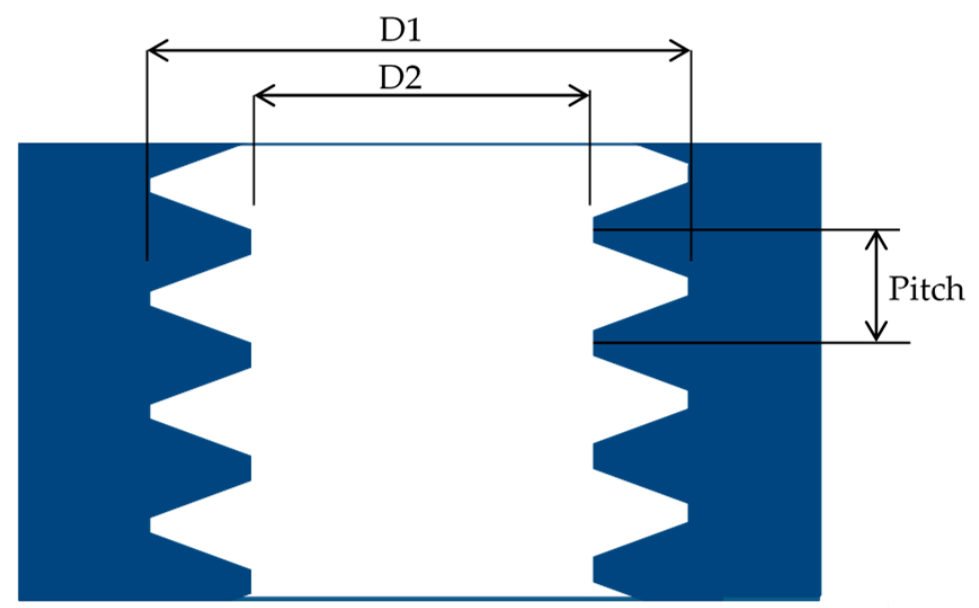

Thread diameter : D1

Screw inner diameter : D2

Thread pitch : Pitch

Figure 1. Measurements used for the analysis of screw teeth.

\section{Related Research}

This section briefly describes the methods applied in the modeling process, including the UD method [16-19], regression analysis [20-23], FPSO [24-28], and Taguchi method [29-36].

\subsection{Uniform Design and Regression Analysis}

The UD method proposed by Fang and Wang $[17,18]$ was used to design and plan experiments in which the test points were evenly distributed within the test range. A uniform layout is expressed as $U_{n}\left(n^{s}\right)$, where $U$ is the uniform layout, $n$ is the level number, and $s$ is the factor number. Table 1 shows the distribution of a $U_{6}\left(6^{6}\right)$ uniform layout.

Table 1. The $U_{6}\left(6^{6}\right)$ uniform layout.

\begin{tabular}{ccccccc}
\hline $\boldsymbol{U}_{\mathbf{6}}\left(\mathbf{6}^{\mathbf{6}}\right)$ & $\mathbf{1}$ & $\mathbf{2}$ & $\mathbf{3}$ & $\mathbf{4}$ & $\mathbf{5}$ & $\mathbf{6}$ \\
\hline 1 & 1 & 2 & 3 & 4 & 5 & 6 \\
2 & 2 & 3 & 6 & 1 & 3 & 5 \\
3 & 3 & 6 & 2 & 5 & 1 & 4 \\
4 & 4 & 1 & 5 & 2 & 6 & 3 \\
5 & 5 & 3 & 1 & 6 & 4 & 2 \\
6 & 6 & 5 & 4 & 3 & 2 & 1 \\
\hline
\end{tabular}

In the UD method, data collected in experiments were used for model building, and data analysis was performed using regression analysis. Regression analysis is a statistical method for analyzing relationships between input variables and output variables. Its main purposes are understanding the relationships among independent variables and dependent variables and then building a mathematical model for predicting dependent variables. Depending on the complexity, a regression analysis can be classified as simple regression and multiple regression. Simple regression uses a single independent variable to predict a dependent variable, and multiple regression explores how a dependent variable is related to multiple independent variables.

The unary linear regression equation expresses the relationship between a dependent variable and an independent variable:

$$
Y=\beta_{0}+\beta_{1 \times 1}+\varepsilon
$$

where $\beta_{0}$ is a constant, $\beta_{1}$ is a regression coefficient, and $\varepsilon$ is an error. 
A multiple linear regression equation expresses the relationship of a dependent variable to multiple independent variables:

$$
Y=\beta_{0}+\beta_{1 \times 1}+\beta_{2 \times 2}+\beta_{3 \times 3}+\ldots+\beta_{m \times m}+\varepsilon
$$

where $\beta_{0}$ is a constant, $\beta_{1}, \beta_{2}, \beta_{3}, \ldots, \beta_{m}$ is a regression coefficient, and $\varepsilon$ is an error.

Regression analysis is often used for the interpretation of experimental data and prediction. For interpretation, the regression equation was calculated from the obtained experimental data. The equation was then used to determine the contribution of each independent variable to the dependent variable. A common application of regression analysis is determining the significance of the independent variable to the dependent variable. Since the regression equation is linear, regression analysis can be used for prediction, i.e., to estimate how an independent variable will change a dependent variable. That is, after regression analysis, a regression model is used to predict a future change in a dependent variable, it can be used to determine how to compensate or respond to the change.

\subsection{Fractional-Order Particle Swarm Optimization (FPSO)}

The FPSO was first proposed by Solteiro Pires et al. [27] and was derived from PSO by introducing the Grünwald-Letnikov fractional-order derivative to enhance its diversity and algorithmic effectiveness. The PSO algorithm [37-41] was inspired by the group behavior of foraging birds and seeks the best solution in the solution space by maximizing or minimizing fitness value, which is analogous to the process in which foraging birds maximize the amount of food they consume. Evolution of position and evolution of speed occur as the optimal parameters for position and speed are updated after each iteration. The calculation formula for PSO is as follows:

$$
\begin{gathered}
V_{i}(k+1)=\omega \cdot V_{i}(k)+c_{1} \cdot r_{1} \cdot\left(P_{i}^{l}(k)-p_{i}(k)\right)+c_{2} \cdot r_{2} \cdot\left(P^{g}(k)-p_{i}(k)\right) \\
p_{i}(k+1)=p_{i}(k)+V_{i}(k+1)
\end{gathered}
$$

where $i=1,2, \ldots, m$ ( $m$ is the number of particles); $k$ is the number of iterations; $w$ is the inertial weight; $V$ is the velocity; $c_{1}$ and $c_{2}$ are individual and group parameters, respectively; $p_{i}(k)$ is the position vector; $P_{i}^{l}(k)$ is the best local solution in the current iteration; $P^{g}(k)$ is the best global solution in the current iteration, and $r_{1}$ and $r_{2}$ are random numbers from 0 to 1 .

Recently, many studies enhanced the performance and effectiveness of PSO, including adjusting the strategies [42,43], particle grouping [44-46], inertia weights [47-49], and other optimization techniques [50-53]. However, PSO has its main drawbacks, such as lack of robustness and tendency to fall into the local optimum. Additionally, the fractional-order derivative describes the real world more than the integer-order one. Therefore, Solteiro Pires et al. [27] involved the fractional-order derivative in PSO to improve the performance and effectiveness, called FPSO. After that, Gao et al. [28] took a nonlinear time-varying inertia weight in FODPSO (Fractional-order Darwinian PSO) to improve. In this paper, the inertial weight was applied to FPSO, and the calculation formula is as follows:

$$
\begin{gathered}
V_{i}(k+1)=\omega \cdot V_{i}(k)+c_{1} \cdot r_{1} \cdot\left(P_{i}^{l}(k)-\lambda \cdot p_{i}(k)-\lambda / 2 \cdot(1-\lambda) \cdot p_{i}(k-1)-\lambda / 6 \cdot(1-\lambda) \cdot(2-\lambda) \cdot p_{i}(k-2)-\lambda / 24 \cdot(1-\right. \\
\left.\lambda) \cdot(2-\lambda) \cdot(3-\lambda) \cdot p_{i}(k-3)\right)+c_{2} \cdot r_{2} \cdot\left(P^{g}(k)-p_{i}(k)\right) \\
p_{i}(k+1)=p_{i}(k)+V_{i}(k+1)
\end{gathered}
$$

where $\lambda$ is the fractional order of the derivative.

\subsection{Taguchi Method}

The purpose of the Taguchi method [29-36] is to achieve a design process in which product quality is stable and insensitive to various noises in the production process. In the product design process, functional relationships among quality, cost, and benefit are 
analyzed to maximize product quality and minimize production costs. A large number of design variables are studied in a small number of experiments. The best combination of design variables can be expressed by the orthogonal table and the signal-noise ratio (SNR). The basic concept of the Taguchi method is to maximize the performance index by using the orthogonal table to perform experiments. Using the orthogonal table reduces experiment time and increases convergence speed. In the Taguchi method, orthogonal arrays and SNR are tools used to optimize the design of engineering parameters in the experimental plan, to reduce variation in important quality characteristics, and to achieve the goal of total cost reduction. Table 2 shows an example of an $L_{9}\left(3^{4}\right)$ orthogonal array that accommodates a maximum of 4 factors with 3 levels per factor.

Table 2. The $L_{9}\left(3^{4}\right)$ orthogonal array.

\begin{tabular}{ccccc}
\hline $\boldsymbol{L}_{\mathbf{9}} \mathbf{3}^{\mathbf{4}} \mathbf{n}$ & $\mathbf{1}$ & $\mathbf{2}$ & $\mathbf{3}$ & $\mathbf{4}$ \\
\hline 1 & 1 & 1 & 1 & 1 \\
2 & 1 & 2 & 2 & 2 \\
3 & 1 & 3 & 3 & 3 \\
4 & 2 & 1 & 2 & 3 \\
5 & 2 & 2 & 3 & 1 \\
6 & 2 & 3 & 1 & 2 \\
7 & 3 & 1 & 3 & 2 \\
8 & 3 & 2 & 1 & 3 \\
9 & 3 & 3 & 2 & 1 \\
\hline
\end{tabular}

The SNR was calculated for quality characteristics, and the goal of this study was the smaller, the better characteristics. The quality function characteristic $Y$ is a non-negative value with a smaller-the-better characteristic; $Y$ can be equal to zero. The SNR of the smaller-the better characteristic is defined as

$$
S N R=-10 \log _{10} \frac{1}{n} \sum_{i=1}^{n}\left(Y_{i}^{2}\right)
$$

\section{Experimental Planning and Methods}

Drilling and tapping processes are used in the manufacturing processes for diverse products ranging from cylinder engines in the automobile industry to mobile phone molds in the consumer electronics industry. Since the manufacture of these products often requires numerous drilling and tapping procedures, determining the parameter combination that provides the best tapping accuracy is needed to achieve high product quality in the postprocess. This study's objective was to find the parameter combination that minimizes rigid tapping synchronization error without increasing manufacturing time.

Figure 2 shows that the experiments were performed in an NDV series machine tool (Yeong-Chin machinery industries Co. Ltd., Taichung, Taiwan) with a FANUC 31iMA controller. The material used for the through-hole processing experiments was polymethyl methacrylate (PMMA) due to its high plasticity, high hardness, and low brittleness. The PMMA was considered an excellent experimental material because it enabled observation of broken or irregular cutters' effects. Therefore, even a significant synchronization error would be unlikely to damage the tapping tool in the tapping axis. The phenomena of stripped thread or thread damage can still be observed in PMMA. An M6 $\times 1$ tapping tool was used in the experiments. The cutting conditions were as follows. Spindle speed, tapping axis feed rate, and tapping depth were set to $3000 \mathrm{RPM}, 3000 \mathrm{~mm} / \mathrm{min}$, and $50 \mathrm{~mm}$, respectively. The experiment was performed five times at these settings. Figure 3 shows the processing path. 


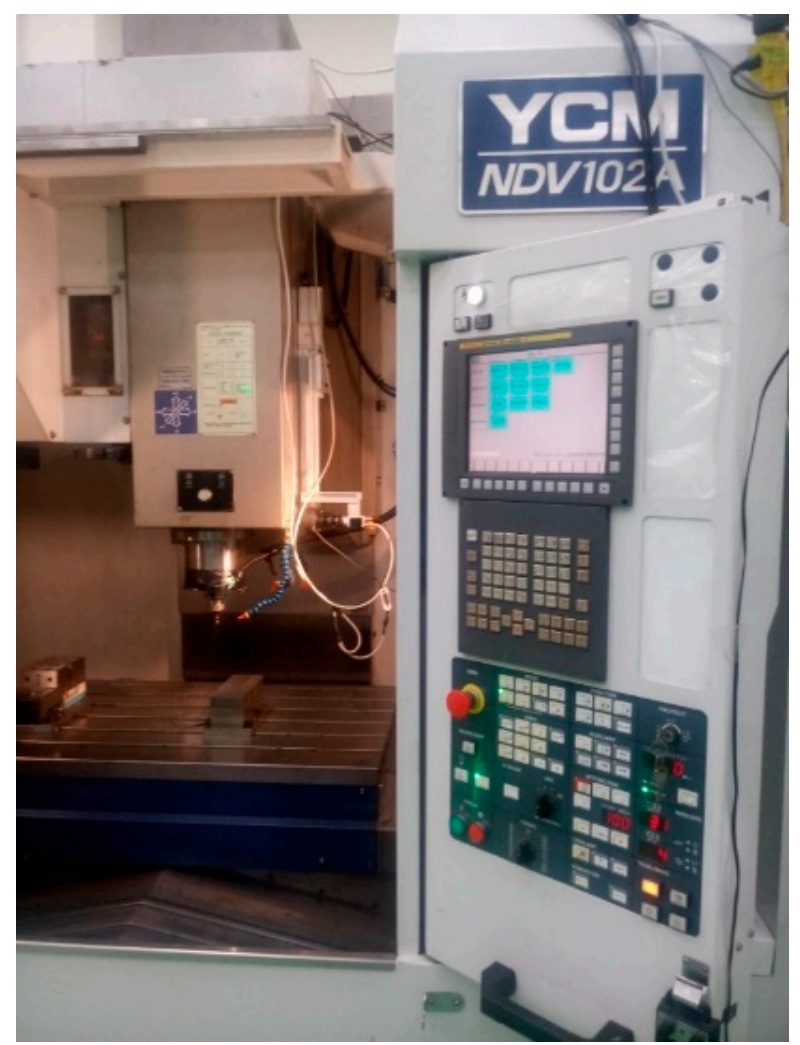

Figure 2. Tapping center machine (YCM NDV102A) used for the experiments in this study.

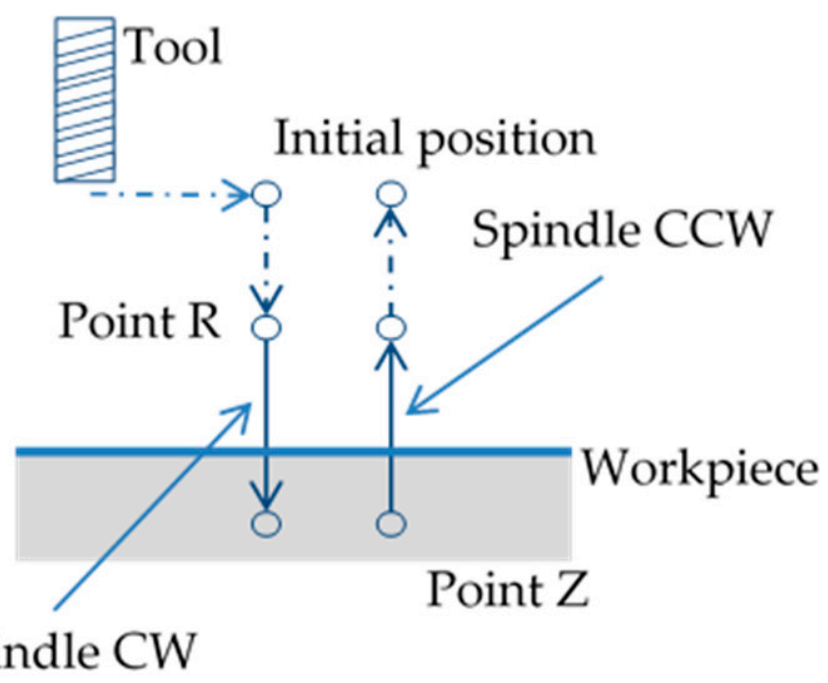

Figure 3. Diagram of rigid tapping path relationship.

The experimental input was the factor that affected synchronization error, and the output was synchronization error. Input factors were factors that affected synchronization error, including feedforward speed coefficient $\left(x_{1}\right.$, unit: $\left.0.01 \%\right)$, rigid tapping speed loop proportional gain $\left(x_{2}\right.$, unit: As), motor excitation delay time ( $x_{3}$, unit: microsecond), rigid tapping speed loop integral gain $\left(x_{4}\right.$, unit: microsecond)), feed position coefficient $\left(x_{5}\right.$, unit: $0.01 \%)$ and tapping axis position gain ( $x_{6}$, unit: $\left.0.01 \mathrm{~s}-1\right)$ [54-57]. These parameters were set on the FANUC controller system.

Figure 4 shows the experimental procedure. The uniform distribution characteristic of UD made each experimental combination meaningful, which substantially reduced the required number of experiments. Table 3 shows the $U{ }^{*}{ }_{28}(288)$ uniform layout selected for this study's experiments. First, input factors were entered in the $U^{*}{ }_{28}$ uniform layout. 
Synchronization error was the quality characteristic, and the response value was obtained by the-smaller-the-better characteristic. Table 4 is the table for selecting column numbers according to the experiment number. Table 4 shows that columns $1-7$ were used to construct the $U^{*}{ }_{28}$ (286) uniform layout, and Table 5 shows the resulting layout. Table 6 shows the 28 levels for each factor. A CCD electronic image microscope was used to observe the results (thread pitch and workpiece shape) of the tapping experiments performed using the factor combinations in Tables 5 and 6 . Table 7 displays the experimental results.

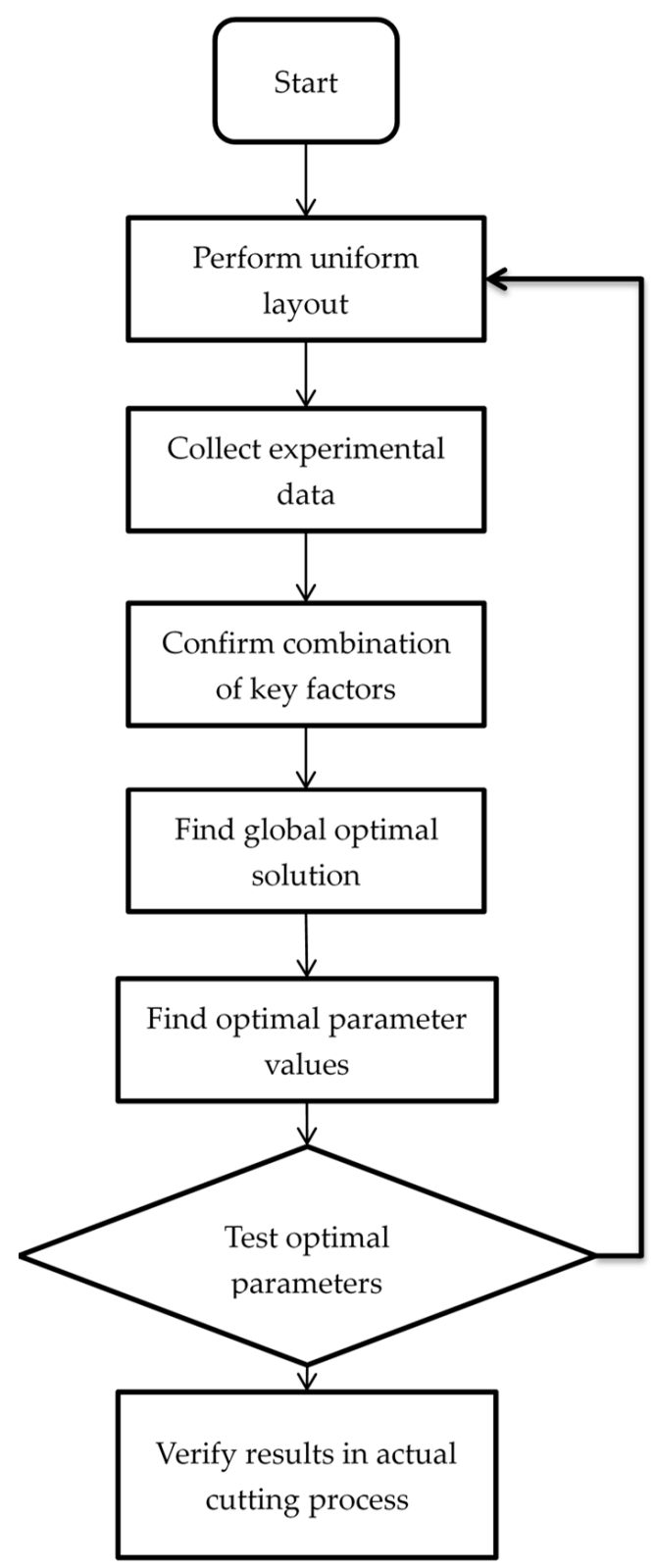

Figure 4. Flowchart of the experimental procedure.

The rigid tapping command for the FANUC 31iMA controller used in the experiments was as follows:

M29 S

G84 X_Y_Z_R_F_K_;

where

M29 is the rigid tapping command,

$\mathrm{S}$ is the spindle speed, G84 is the right-hand thread tapping by M3 spindle rotation, $\mathrm{X}, \mathrm{Y}$ are the hole positions in the $\mathrm{X}$ - and $\mathrm{Y}$-axes, 
$\mathrm{Z}$ is the tapping depth from the R-plane to Z-depth,

$\mathrm{R}$ is the $\mathrm{R}$ plane position,

$\mathrm{F}$ is the tapping axis feed rate, and

$\mathrm{K}$ is the number of cycles.

The rigid tapping program was as follows:

G91 G94

N1

N2 M29 S3000

G84 Z-50.000 R-20.000 F3000.000 K5

G80

G04 X1.N999 G04 X1.

M99

Table 3. The $U^{*}{ }_{28}\left(28^{8}\right)$ uniform layout.

\begin{tabular}{ccccccccc}
\hline $\boldsymbol{U}^{*}{ }_{28}\left(\mathbf{2 8} \mathbf{8}^{\mathbf{}}\right.$ & $\mathbf{1}$ & $\mathbf{2}$ & $\mathbf{3}$ & $\mathbf{4}$ & $\mathbf{5}$ & $\mathbf{6}$ & $\mathbf{7}$ & $\mathbf{8}$ \\
\hline 1 & 1 & 7 & 16 & 18 & 20 & 23 & 24 & 25 \\
2 & 2 & 14 & 3 & 7 & 11 & 17 & 19 & 21 \\
3 & 3 & 21 & 19 & 25 & 2 & 11 & 14 & 17 \\
4 & 4 & 28 & 6 & 14 & 22 & 5 & 9 & 13 \\
5 & 5 & 6 & 22 & 3 & 13 & 28 & 4 & 9 \\
6 & 6 & 13 & 9 & 21 & 4 & 22 & 28 & 5 \\
7 & 7 & 20 & 25 & 10 & 24 & 16 & 23 & 1 \\
8 & 8 & 27 & 12 & 28 & 15 & 10 & 18 & 26 \\
9 & 9 & 5 & 28 & 17 & 6 & 4 & 13 & 22 \\
10 & 10 & 12 & 15 & 6 & 26 & 27 & 8 & 18 \\
11 & 11 & 19 & 2 & 24 & 17 & 21 & 3 & 14 \\
12 & 12 & 26 & 18 & 13 & 8 & 15 & 27 & 10 \\
13 & 13 & 4 & 5 & 2 & 28 & 9 & 22 & 6 \\
14 & 14 & 11 & 21 & 20 & 19 & 3 & 17 & 2 \\
15 & 15 & 18 & 8 & 9 & 10 & 26 & 12 & 27 \\
16 & 16 & 25 & 24 & 27 & 1 & 20 & 7 & 23 \\
17 & 17 & 3 & 11 & 16 & 21 & 14 & 2 & 19 \\
18 & 18 & 10 & 27 & 5 & 12 & 8 & 26 & 15 \\
19 & 19 & 17 & 14 & 23 & 3 & 2 & 21 & 11 \\
20 & 20 & 24 & 1 & 12 & 23 & 25 & 16 & 7 \\
21 & 21 & 2 & 17 & 1 & 14 & 19 & 11 & 3 \\
22 & 22 & 9 & 4 & 19 & 5 & 13 & 6 & 28 \\
23 & 23 & 16 & 20 & 8 & 25 & 7 & 1 & 24 \\
24 & 24 & 23 & 7 & 26 & 16 & 1 & 25 & 20 \\
25 & 25 & 1 & 23 & 15 & 7 & 24 & 20 & 16 \\
26 & 26 & 8 & 10 & 4 & 27 & 18 & 15 & 12 \\
27 & 27 & 15 & 26 & 22 & 18 & 12 & 10 & 8 \\
28 & 28 & 22 & 13 & 11 & 9 & 6 & 5 & 4 \\
\hline
\end{tabular}

Table 4. Table for selecting column numbers for the $U{ }^{*} 28$ uniform layout.

\begin{tabular}{cc}
\hline Number of Factors & Column \\
\hline 2 & 14 \\
3 & 125 \\
4 & 1257 \\
5 & 12378 \\
6 & 123567 \\
7 & 1235678 \\
\hline
\end{tabular}


Table 5. The $U{ }^{*}{ }_{28}\left(28^{6}\right)$ uniform layout implemented in this study.

\begin{tabular}{ccccccc}
\hline $\boldsymbol{U}^{*} \mathbf{2 8}^{\mathbf{2}} \mathbf{8}^{\mathbf{8}} \mathbf{n}$ & $\mathbf{1}$ & $\mathbf{2}$ & $\mathbf{3}$ & $\mathbf{5}$ & $\mathbf{6}$ & $\mathbf{7}$ \\
\hline 1 & 1 & 7 & 16 & 20 & 23 & 24 \\
2 & 2 & 14 & 3 & 11 & 17 & 19 \\
3 & 3 & 21 & 19 & 2 & 11 & 14 \\
4 & 4 & 28 & 6 & 22 & 5 & 9 \\
5 & 5 & 6 & 22 & 13 & 28 & 4 \\
6 & 6 & 13 & 9 & 4 & 22 & 28 \\
7 & 7 & 20 & 25 & 24 & 16 & 23 \\
8 & 8 & 27 & 12 & 15 & 10 & 18 \\
9 & 9 & 5 & 28 & 6 & 4 & 13 \\
10 & 10 & 12 & 15 & 26 & 27 & 8 \\
11 & 11 & 19 & 2 & 17 & 21 & 3 \\
12 & 12 & 26 & 18 & 8 & 15 & 27 \\
13 & 13 & 4 & 5 & 28 & 9 & 22 \\
14 & 14 & 11 & 21 & 19 & 3 & 17 \\
15 & 15 & 18 & 8 & 10 & 26 & 12 \\
16 & 16 & 25 & 24 & 1 & 20 & 7 \\
17 & 17 & 3 & 11 & 21 & 14 & 2 \\
18 & 18 & 10 & 27 & 12 & 8 & 26 \\
19 & 19 & 17 & 14 & 3 & 2 & 21 \\
20 & 20 & 24 & 1 & 23 & 25 & 16 \\
21 & 21 & 2 & 17 & 14 & 19 & 11 \\
22 & 22 & 9 & 4 & 5 & 13 & 6 \\
23 & 23 & 16 & 20 & 25 & 7 & 1 \\
24 & 24 & 23 & 7 & 16 & 1 & 25 \\
25 & 25 & 1 & 23 & 7 & 24 & 20 \\
26 & 26 & 8 & 10 & 27 & 18 & 15 \\
27 & 27 & 15 & 26 & 18 & 12 & 10 \\
28 & 28 & 22 & 13 & 9 & 6 & 5 \\
\hline & & & & & & \\
\hline
\end{tabular}

Table 6. Level-cut for rigid tapping factors.

\begin{tabular}{|c|c|c|c|c|c|c|}
\hline & $x_{1}$ & $x_{2}$ & $x_{3}$ & $x_{4}$ & $x_{5}$ & $x_{6}$ \\
\hline Level & $\begin{array}{l}\text { Velocity Feed } \\
\text { Forward } \\
\text { Coefficient }\end{array}$ & $\begin{array}{l}\text { Proportional Gain of } \\
\text { Velocity Loop for } \\
\text { Spindle in Servo Mode }\end{array}$ & $\begin{array}{l}\text { Delay Time } \\
\text { for Motor } \\
\text { Excitation }\end{array}$ & $\begin{array}{c}\text { Integral Gain of } \\
\text { Velocity Loop for } \\
\text { Spindle in Servo Mode }\end{array}$ & $\begin{array}{l}\text { Advanced } \\
\text { Feed } \\
\text { Forward }\end{array}$ & $\begin{array}{l}\text { Position Gain of } \\
\text { Servo Axis for } \\
\text { Rigid Tap }\end{array}$ \\
\hline 1 & 30 & 23 & 200 & 100 & 2500 & 3455 \\
\hline 2 & 47 & 24 & 206 & 106 & 2778 & 3694 \\
\hline 3 & 64 & 25 & 212 & 112 & 3056 & 3933 \\
\hline 4 & 81 & 26 & 218 & 118 & 3334 & 4172 \\
\hline 5 & 98 & 27 & 224 & 124 & 3612 & 4411 \\
\hline 6 & 115 & 28 & 230 & 130 & 3890 & 4650 \\
\hline 7 & 132 & 29 & 236 & 136 & 4168 & 4889 \\
\hline 8 & 149 & 30 & 242 & 142 & 4446 & 5128 \\
\hline 9 & 166 & 31 & 248 & 148 & 4724 & 5367 \\
\hline 10 & 183 & 32 & 254 & 154 & 5002 & 5606 \\
\hline 11 & 200 & 33 & 260 & 160 & 5280 & 5845 \\
\hline 12 & 217 & 34 & 266 & 166 & 5558 & 6084 \\
\hline 13 & 234 & 35 & 272 & 172 & 5836 & 6323 \\
\hline 14 & 251 & 36 & 278 & 178 & 6114 & 6562 \\
\hline 15 & 268 & 37 & 284 & 184 & 6392 & 6801 \\
\hline 16 & 285 & 38 & 290 & 190 & 6670 & 7040 \\
\hline 17 & 302 & 39 & 296 & 196 & 6948 & 7279 \\
\hline 18 & 319 & 40 & 302 & 202 & 7226 & 7518 \\
\hline 19 & 336 & 41 & 308 & 208 & 7504 & 7757 \\
\hline 20 & 353 & 42 & 314 & 214 & 7782 & 7996 \\
\hline 21 & 370 & 43 & 320 & 220 & 8060 & 8235 \\
\hline 22 & 387 & 44 & 326 & 226 & 8338 & 8474 \\
\hline 23 & 404 & 45 & 332 & 232 & 8616 & 8713 \\
\hline 24 & 421 & 46 & 338 & 238 & 8894 & 8952 \\
\hline 25 & 438 & 47 & 344 & 244 & 9172 & 9191 \\
\hline 26 & 455 & 48 & 350 & 250 & 9450 & 9430 \\
\hline 27 & 472 & 49 & 356 & 256 & 9728 & 9669 \\
\hline 28 & 489 & 50 & 362 & 262 & 10,000 & 9908 \\
\hline
\end{tabular}


Table 7. The $U{ }^{*}{ }_{28}\left(28^{6}\right)$ uniform layout implemented in this study.

\begin{tabular}{ccccccc}
\hline No. & $\boldsymbol{x}_{\mathbf{1}}$ & $\boldsymbol{x}_{\mathbf{2}}$ & $\boldsymbol{x}_{\mathbf{3}}$ & $\boldsymbol{x}_{\mathbf{4}}$ & $\boldsymbol{x}_{\mathbf{5}}$ & $\boldsymbol{x}_{\mathbf{6}}$ \\
\hline 1 & 30 & 29 & 290 & 214 & 8616 & 8952 \\
2 & 47 & 36 & 212 & 160 & 6948 & 7757 \\
3 & 64 & 43 & 308 & 106 & 5280 & 6562 \\
4 & 81 & 50 & 230 & 226 & 3612 & 5367 \\
5 & 98 & 28 & 326 & 172 & 10,000 & 4172 \\
6 & 115 & 35 & 248 & 118 & 8338 & 9908 \\
7 & 132 & 42 & 344 & 238 & 6670 & 8713 \\
8 & 149 & 49 & 266 & 184 & 5002 & 7518 \\
9 & 166 & 27 & 362 & 130 & 3334 & 6323 \\
10 & 183 & 34 & 284 & 250 & 9728 & 5128 \\
11 & 200 & 41 & 206 & 196 & 8060 & 3933 \\
12 & 217 & 48 & 302 & 142 & 6392 & 9669 \\
13 & 234 & 26 & 224 & 262 & 4724 & 8474 \\
14 & 251 & 33 & 320 & 208 & 3056 & 7279 \\
15 & 268 & 40 & 242 & 154 & 9450 & 6084 \\
16 & 285 & 47 & 338 & 100 & 7782 & 4889 \\
17 & 302 & 25 & 260 & 220 & 6114 & 3694 \\
18 & 319 & 32 & 356 & 166 & 4446 & 9430 \\
19 & 336 & 39 & 278 & 112 & 2778 & 8235 \\
20 & 353 & 46 & 200 & 232 & 9172 & 7040 \\
21 & 370 & 24 & 296 & 178 & 7504 & 5845 \\
22 & 387 & 31 & 218 & 124 & 5836 & 4650 \\
23 & 404 & 38 & 314 & 224 & 4168 & 3455 \\
24 & 421 & 45 & 236 & 190 & 9172 & 9191 \\
25 & 438 & 23 & 332 & 136 & 8894 & 7996 \\
26 & 455 & 30 & 254 & 256 & 7226 & 6801 \\
27 & 472 & 37 & 350 & 202 & 5558 & 5606 \\
28 & 489 & 44 & 272 & 148 & 3890 & 4411 \\
\hline
\end{tabular}

Table 8 presents the results obtained by the $U{ }^{*}{ }_{28}\left(28^{6}\right)$ uniform layout. Based on the regression analysis results and the experimental results in Table 8, the following regression equation was obtained:

$$
\begin{gathered}
y=180.116319-3.143699 x_{2}-0.023775 x_{6}+0.008271 x_{2} x_{3}+0.000115 x_{4} x_{5}+0.000450 x_{2} x_{6}+2.93 \times 10^{-6} \\
x_{5} x_{6}-4.18 \times 10^{-7} x_{3} x_{4} x_{5}-6.61 \times 10^{-8} x_{2} x_{5} x_{6}
\end{gathered}
$$

According to Equation (9), the key factors in synchronization error in rigid tapping are $x_{2}$ (rigid tapping speed loop proportional gain), $x_{3}$ (motor excitation delay time), $x_{4}$ (rigid tapping speed loop integral gain), $x_{5}$ (position feed coefficient) and $x_{6}$ (tapping axis position gain). Next, FPSO was used to find the global best combination of values for factors $x_{2}, x_{3}, x_{4}, x_{5}$, and $x_{6}$ and to find the global best output value. According to the FPSO results, the global best combination was $\left(x_{2}, x_{3}, x_{4}, x_{5}, x_{6}\right)=(50,360,260,9400,9400)$, and the global best output value was 39.9329 .

Next, the Taguchi method was used to verify the global best combination obtained by UD and FPSO. Table 9 is the $L^{\prime}{ }_{16}\left(4^{5}\right)$ orthogonal array selected for this number of factors. Here, the levels of the $L_{16}^{\prime}\left(4^{5}\right)$ orthogonal array were based on the global best combination obtained by UD and FPSO. Table 10 shows the values for $x_{2}, x_{3}, x_{4}, x_{5}$, and $x_{6}$, and Table 11 shows the factor combinations of $L_{16}^{\prime}\left(4^{5}\right)$. The values in Table 11 were used to obtain the results shown in Table 12. Table 13 and Figure 5 are the response table and figure, respectively, which show that the best combination of values for $x_{2}, x_{3}, x_{4}, x_{5}$, and $x_{6}$ was 55 , $355,260,7900$, and 9900, respectively. 
Table 8. Results based on $U^{*}{ }_{28}\left(28^{6}\right)$ uniform layout.

\begin{tabular}{cccccccc}
\hline No. & $\boldsymbol{x}_{\mathbf{1}}$ & $\boldsymbol{x}_{\mathbf{2}}$ & $\boldsymbol{x}_{\mathbf{3}}$ & $\boldsymbol{x}_{\mathbf{4}}$ & $\boldsymbol{x}_{\mathbf{5}}$ & $\boldsymbol{x}_{\mathbf{6}}$ & Sync Error \\
\hline 1 & 30 & 29 & 290 & 214 & 8616 & 8952 & 511.8 \\
2 & 47 & 36 & 212 & 160 & 6948 & 7757 & 1303.2 \\
3 & 64 & 43 & 308 & 106 & 5280 & 6562 & 2375.2 \\
4 & 81 & 50 & 230 & 226 & 3612 & 5367 & 3909 \\
5 & 98 & 28 & 326 & 172 & 10,000 & 4172 & 21.4 \\
6 & 115 & 35 & 248 & 118 & 8338 & 9908 & 560 \\
7 & 132 & 42 & 344 & 238 & 6670 & 8713 & 1270 \\
8 & 149 & 49 & 266 & 184 & 5002 & 7518 & 2205.6 \\
9 & 166 & 27 & 362 & 130 & 3334 & 6323 & 3479.8 \\
10 & 183 & 34 & 284 & 250 & 9728 & 5128 & 178.4 \\
11 & 200 & 41 & 206 & 196 & 8060 & 3933 & 1609 \\
12 & 217 & 48 & 302 & 142 & 6392 & 9669 & 1247 \\
13 & 234 & 26 & 224 & 262 & 4724 & 8474 & 2070 \\
14 & 251 & 33 & 320 & 208 & 3056 & 7279 & 3161.2 \\
15 & 268 & 40 & 242 & 154 & 9450 & 6084 & 310 \\
16 & 285 & 47 & 338 & 100 & 7782 & 4889 & 1503 \\
17 & 302 & 25 & 260 & 220 & 6114 & 3694 & 3423.4 \\
18 & 319 & 32 & 356 & 166 & 4446 & 9430 & 1963.8 \\
19 & 336 & 39 & 278 & 112 & 2778 & 8235 & 2915.6 \\
20 & 353 & 46 & 200 & 232 & 9172 & 7040 & 409 \\
21 & 370 & 24 & 296 & 178 & 7504 & 5845 & 1425.8 \\
22 & 387 & 31 & 218 & 124 & 5836 & 4650 & 2651.2 \\
23 & 404 & 38 & 314 & 224 & 4168 & 3455 & 5470.6 \\
24 & 421 & 45 & 236 & 190 & 9172 & 9191 & 2719.4 \\
25 & 438 & 23 & 332 & 136 & 8894 & 7996 & 488.8 \\
26 & 455 & 30 & 254 & 256 & 7226 & 6801 & 1374.2 \\
27 & 472 & 37 & 350 & 202 & 5558 & 5606 & 2627.4 \\
28 & 489 & 44 & 272 & 148 & 3890 & 4411 & 4540.4 \\
\hline
\end{tabular}

Table 9. The $L_{16}^{\prime}\left(4^{5}\right)$ orthogonal array.

\begin{tabular}{cccccc}
\hline No. & $\mathbf{1}$ & $\mathbf{2}$ & $\mathbf{3}$ & $\mathbf{4}$ & $\mathbf{5}$ \\
\hline 1 & 1 & 1 & 1 & 1 & 1 \\
2 & 1 & 2 & 2 & 2 & 2 \\
3 & 1 & 3 & 3 & 3 & 3 \\
4 & 1 & 4 & 4 & 4 & 4 \\
5 & 2 & 1 & 2 & 3 & 4 \\
6 & 2 & 2 & 1 & 4 & 3 \\
7 & 2 & 3 & 4 & 1 & 2 \\
8 & 2 & 4 & 2 & 1 \\
9 & 3 & 1 & 3 & 4 & 2 \\
10 & 3 & 2 & 4 & 3 & 4 \\
11 & 3 & 3 & 1 & 2 & 3 \\
12 & 3 & 4 & 2 & 1 & 3 \\
13 & 4 & 1 & 3 & 2 & 4 \\
14 & 4 & 2 & 2 & 4 & 2 \\
15 & 4 & 3 & 1 & 3 & \\
16 & 4 & 4 & & & 4 \\
\hline
\end{tabular}

Table 10. The $L_{16}^{\prime}\left(4^{5}\right)$ orthogonal array with level value for each factor.

\begin{tabular}{cccccc}
\hline No. & $x_{2}$ & $x_{3}$ & $x_{4}$ & $x_{5}$ & $x_{6}$ \\
\hline 1 & 40 & 350 & 245 & 6900 & 9600 \\
2 & 45 & 355 & 250 & 7900 & 9700 \\
3 & 50 & 360 & 255 & 8900 & 9800 \\
4 & 55 & 365 & 260 & 9900 & 9900 \\
\hline
\end{tabular}


Table 11. An $L^{\prime}{ }_{16}\left(4^{5}\right)$ orthogonal array with level value for each factor.

\begin{tabular}{cccccc}
\hline No. & $\boldsymbol{x}_{\mathbf{2}}$ & $\boldsymbol{x}_{\mathbf{3}}$ & $\boldsymbol{x}_{\mathbf{4}}$ & $\boldsymbol{x}_{\mathbf{5}}$ & $\boldsymbol{x}_{\mathbf{6}}$ \\
\hline 1 & 40 & 350 & 245 & 6900 & 9600 \\
2 & 40 & 355 & 250 & 7900 & 9700 \\
3 & 40 & 360 & 255 & 8900 & 9800 \\
4 & 40 & 365 & 260 & 9900 & 9900 \\
5 & 45 & 350 & 250 & 8900 & 9900 \\
6 & 45 & 355 & 245 & 9900 & 9800 \\
7 & 45 & 360 & 260 & 6900 & 9700 \\
8 & 45 & 365 & 255 & 7900 & 9600 \\
9 & 50 & 350 & 255 & 9900 & 9700 \\
10 & 50 & 355 & 260 & 8900 & 9600 \\
11 & 50 & 360 & 245 & 7900 & 9900 \\
12 & 50 & 365 & 250 & 6900 & 9800 \\
13 & 55 & 350 & 260 & 7900 & 9800 \\
14 & 55 & 355 & 255 & 6900 & 9900 \\
15 & 55 & 360 & 250 & 9900 & 9600 \\
16 & 55 & 365 & 245 & 8900 & 9700 \\
\hline
\end{tabular}

Table 12. Results for $L^{\prime}{ }_{16}\left(4^{5}\right)$ orthogonal array.

\begin{tabular}{|c|c|c|c|c|c|c|c|c|c|c|c|c|c|}
\hline \multirow{2}{*}{ No. } & \multicolumn{5}{|c|}{ Factors } & \multicolumn{5}{|c|}{ Results } & \multirow{2}{*}{ Avg. 1} & \multirow{2}{*}{ RMSD $^{2}$} & \multirow{2}{*}{$\mathbf{H}^{3}$} \\
\hline & $x_{2}$ & $x_{3}$ & $x_{4}$ & $x_{5}$ & $x_{6}$ & 1 & 2 & 3 & 4 & 5 & & & \\
\hline 1 & 40 & 350 & 245 & 6900 & 9600 & 10.5 & 10.5 & 11 & 11 & 10.5 & 10.7 & 114.55 & -20.59 \\
\hline 2 & 40 & 355 & 250 & 7900 & 9700 & 10 & 10 & 9.5 & 10 & 9.5 & 9.8 & 96.1 & -19.8272 \\
\hline 3 & 40 & 360 & 255 & 8900 & 9800 & 10.5 & 10 & 10.5 & 11 & 11.5 & 10.7 & 114.75 & -20.5975 \\
\hline 4 & 40 & 365 & 260 & 9900 & 9900 & 10 & 10.5 & 9.5 & 10 & 10 & 10 & 100.1 & -20.0043 \\
\hline 5 & 45 & 350 & 250 & 8900 & 9900 & 10 & 10 & 10 & 10 & 10 & 10 & 100 & -20 \\
\hline 6 & 45 & 355 & 245 & 9900 & 9800 & 8.5 & 8 & 8 & 8.5 & 8.5 & 8.3 & 68.95 & -18.3853 \\
\hline 7 & 45 & 360 & 260 & 6900 & 9700 & 9 & 9.5 & 9 & 9 & 9.5 & 9.2 & 84.7 & -19.2788 \\
\hline 8 & 45 & 365 & 255 & 7900 & 9600 & 9.5 & 8 & 8.5 & 8.5 & 8.5 & 8.6 & 74.2 & -18.704 \\
\hline 9 & 50 & 350 & 255 & 9900 & 9700 & 8 & 8.5 & 8.5 & 8 & 8 & 8.2 & 67.3 & -18.2802 \\
\hline 10 & 50 & 355 & 260 & 8900 & 9600 & 8 & 8 & 7 & 7.5 & 7.5 & 7.6 & 57.9 & -17.6268 \\
\hline 11 & 50 & 360 & 245 & 7900 & 9900 & 7.5 & 7.5 & 7.5 & 7.5 & 7.5 & 7.5 & 56.25 & -17.5012 \\
\hline 12 & 50 & 365 & 250 & 6900 & 9800 & 8 & 8 & 8 & 7.5 & 8 & 7.9 & 62.45 & -17.9553 \\
\hline 13 & 55 & 350 & 260 & 7900 & 9800 & 6 & 6 & 6 & 5.5 & 6 & 5.9 & 34.85 & -15.422 \\
\hline 14 & 55 & 355 & 255 & 6900 & 9900 & 6 & 6.5 & 7 & 7 & 7.5 & 6.8 & 46.5 & -16.6745 \\
\hline 15 & 55 & 360 & 250 & 9900 & 9600 & 6.5 & 6.5 & 6.5 & 6.5 & 6.5 & 6.5 & 42.25 & -16.2583 \\
\hline 16 & 55 & 365 & 245 & 8900 & 9700 & 7.5 & 6.5 & 6.5 & 6.5 & 6.5 & 6.7 & 45.05 & -16.5369 \\
\hline
\end{tabular}

${ }^{1}$ Avg: Average value in experiments. ${ }^{2}$ RMSD: Root-mean-square deviation. ${ }^{3} \eta$ : Signal-to-noise ratio.

Table 13. Response table for $L^{\prime}{ }_{16}\left(4^{5}\right)$ orthogonal array results in Table 12.

\begin{tabular}{cccccc}
\hline No. & $x_{2}$ & $x_{3}$ & $x_{4}$ & $x_{5}$ & $x_{6}$ \\
\hline 1 & -20.2548 & -18.573 & -18.3763 & -18.6247 & -18.2948 \\
2 & -19.0921 & -18.1285 & -18.5102 & -17.8636 & -18.6037 \\
3 & -17.8409 & -18.409 & -18.5641 & -18.8132 & -18.0901 \\
4 & -16.3459 & -18.4231 & -18.083 & -18.232 & -13.2319 \\
\hline
\end{tabular}

Figure 6 displays the rigid tapping errors obtained under the optimal parameter combination. Synchronization error was 23 pulses before adjustment and 18 pulses after adjustment. For verification, the simulation results and actual processing results were compared before and after optimization. The optimal combination was then used in an actual thread cutting process. After the process was performed five times, the bolt was cut in half with a face milling cutter, and the workpiece was placed under a CCD electronic image microscope to observe its shape and measure the pitch and appearance of the thread. 
The outer diameter (D1) and inner diameter (D2) of the thread were measured, and the difference between D1 and D2 was obtained. Table 14 shows that a significant difference between D1 and D2 indicated that the screw teeth were well-shaped and that the potential for tooth collapse was minimal.

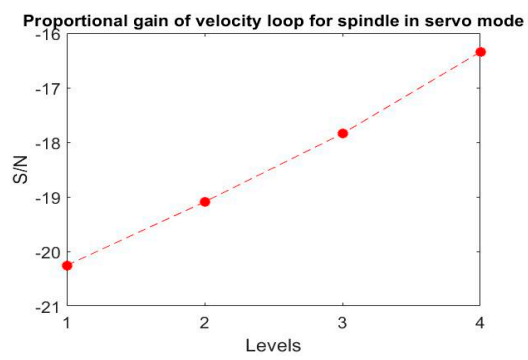

(a)

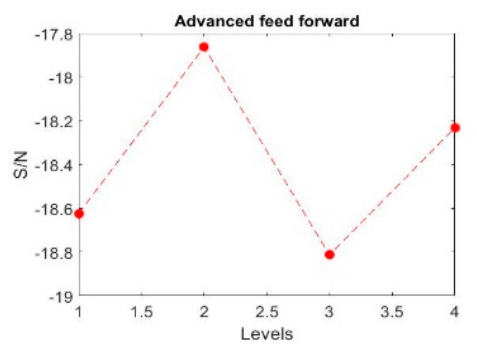

(d)

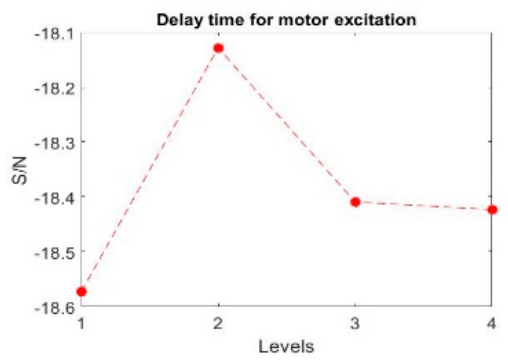

(b)

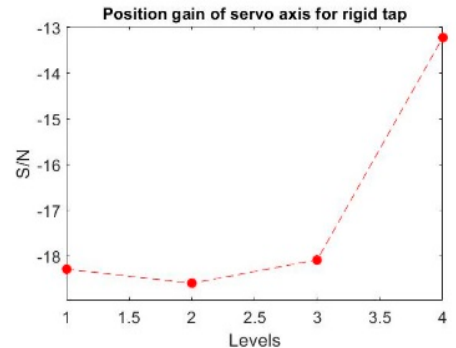

(e)

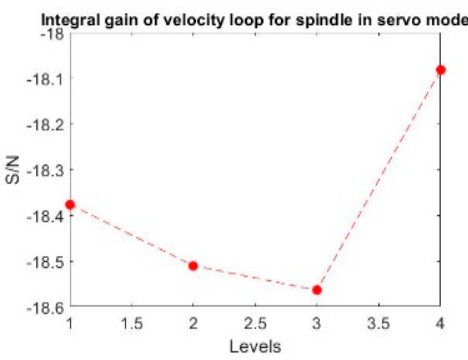

(c)

Figure 5. Response table from Table 13. (a) Proportional gain of velocity loop for spindle in servo mode; (b) Delay time for motor excitation; (c) Integral gain of velocity loop for spindle in servo mode; (d) Advanced feedforward; (e) Position gain of servo axis for rigid tap.

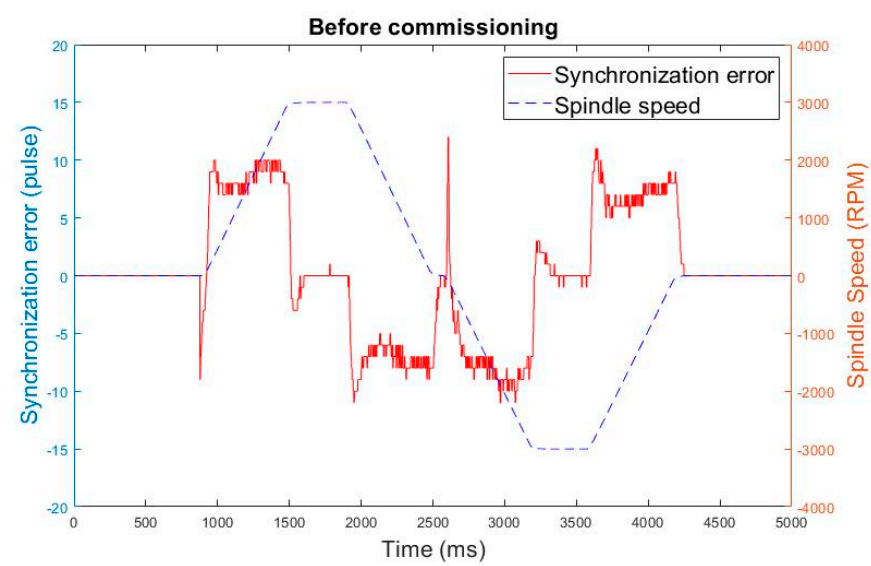

(a)

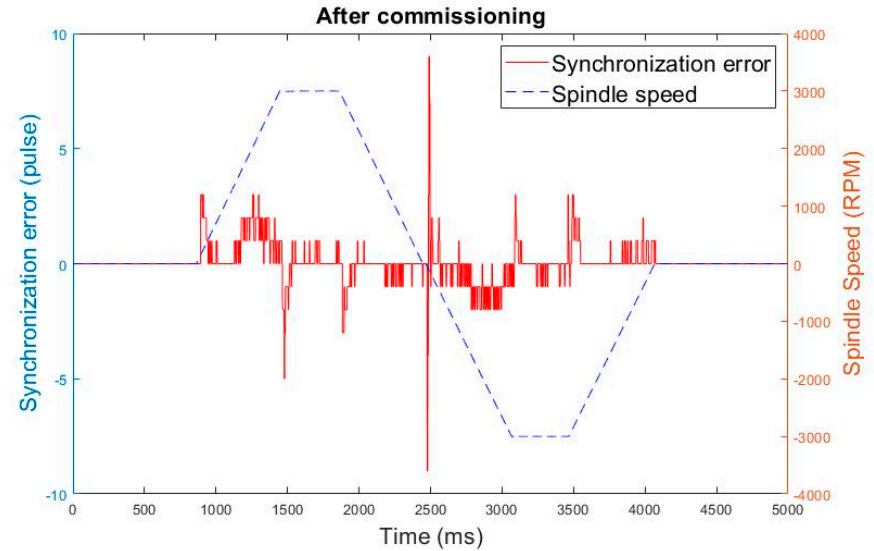

(b)

Figure 6. Synchronization error waveforms in rigid tapping before (a) and after commissioning (b).

Conversely, a slight difference indicated poorly-shaped screw teeth and a high potential for tooth collapse. Screw thread pitch was also measured to determine whether disordered teeth had caused an excessive error during the same period. Table 14 shows that the proposed method obtained superior tapping results compared to the results obtained without optimizing rigid tapping electrical control parameters. 
Table 14. Difference between outer diameter (D1) and inner diameter (D2) before and after commissioning.

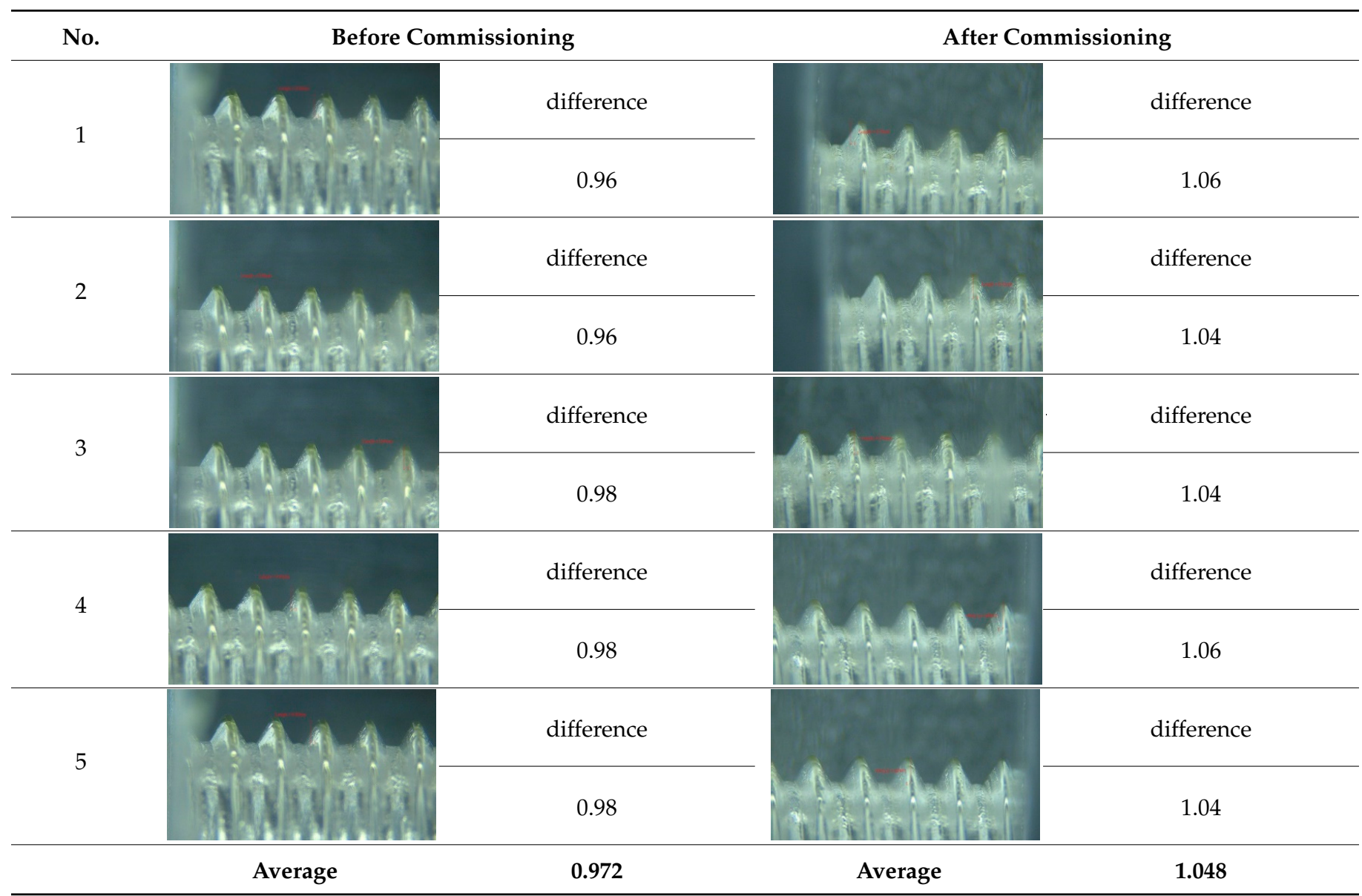

\section{Conclusions}

The proposed hybrid method for optimizing synchronization in rigid tapping was verified in an actual thread cutting process. Errors in synchronization of the spindle and the tapping axis were captured, and parameter values were adjusted for optimal synchronization.

Rigid tapping is easily performed when the CNC machine tool used for spiral tapping is operated at the expected speed and feed rate. However, high synchronization of motion is required to achieve a high-quality tap and avoid damage to the tapping tool and the workpiece. Therefore, the UD method proposed in this study integrated regression analysis, FPSO, and the Taguchi method to optimize rigid tapping parameters and obtained excellent tapping results.

For parameters $x_{2}, x_{3}, x_{4}, x_{5}, x_{6}$, the optimal combination of values was 55,355 , 260,7900 , and 9900 , respectively. This combination reduced synchronization error from 23 pulses under the original parameters to 18 pulses, which was a $22 \%$ improvement in accuracy. The optimized combination also reduced processing time from 20,880 $\mathrm{ms}$ to 20,033 ms.

The method proposed in this study improves machining accuracy by determining the critical factors in rigid tapping synchronization error and the optimal values for the key factors. Additionally, the proposed method reduces the potential for damage to the workpiece during a tapping procedure and reduces the time required for parameter commissioning. The four main findings of the experiments were as follows:

1. The proportional gain and integral gain of the spindle can be adjusted to increase its rigidity during rigid tapping.

2. Adjusting the position gain of the tapping axis and the feedforward coefficient can substantially decrease synchronization errors. Figures 7 and 8 show how to position 
gain affects synchronization error and torque command. When position gain is significant, synchronization error is small, but current increases. Notably, the present value during air cut commissioning should not exceed $70-80 \%$, and a reserve margin should be set to avoid overheating or overloading the motor during actual cutting. Air cut commissioning means dry run commissioning. Figures 9 and 10 compare the effects of different feedforward coefficients on torque command.

3. Adjusting the time required for motor excitation and stabilization can reduce errors at the start of rigid tapping.

4. Reducing the $z$-axis following error, the synchronization error of rigid tapping can get better performance. After a synchronization error, reducing the $z$-axis following error and commissioning proportional gain, integral gain, and position gain can improve rigid tapping precision.

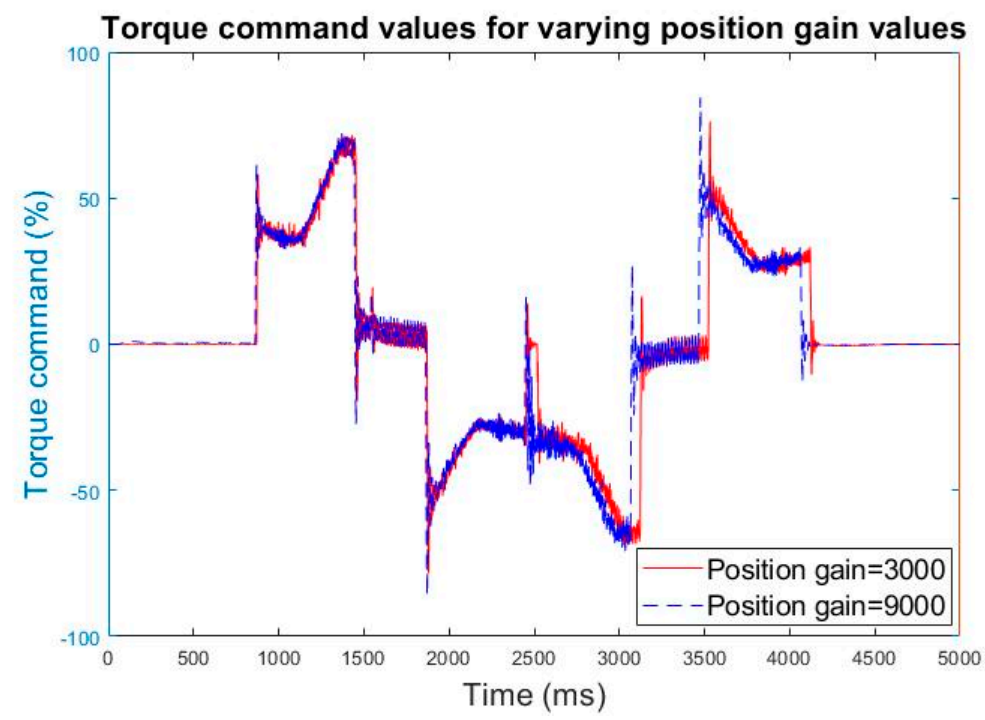

Figure 7. Torque command values for varying position gain values in rigid tapping.

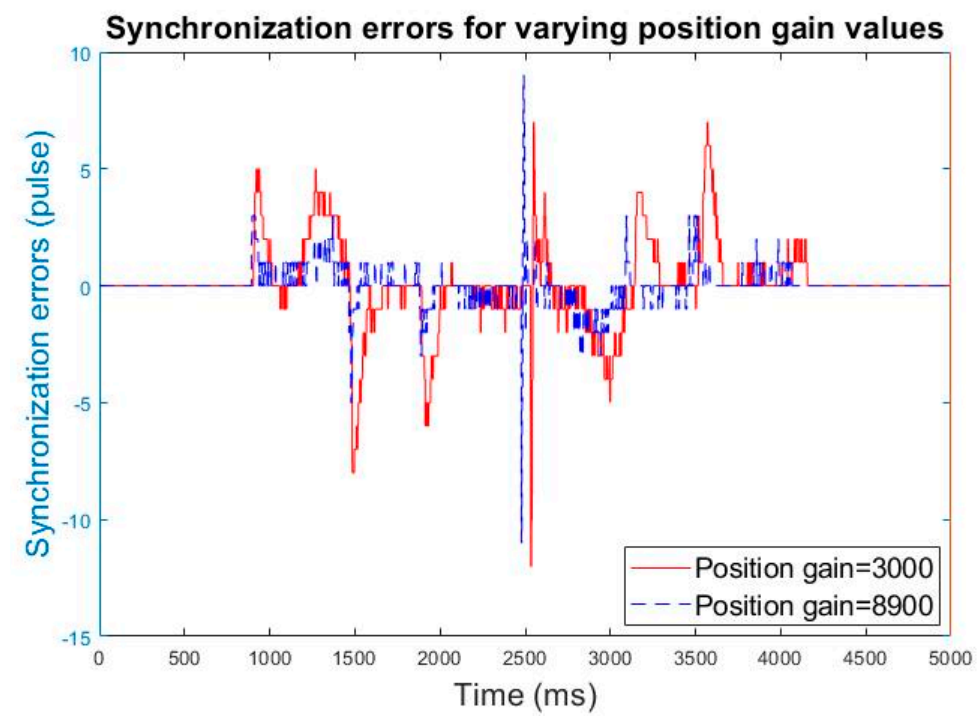

Figure 8. Synchronization errors for varying position gain values in rigid tapping. 


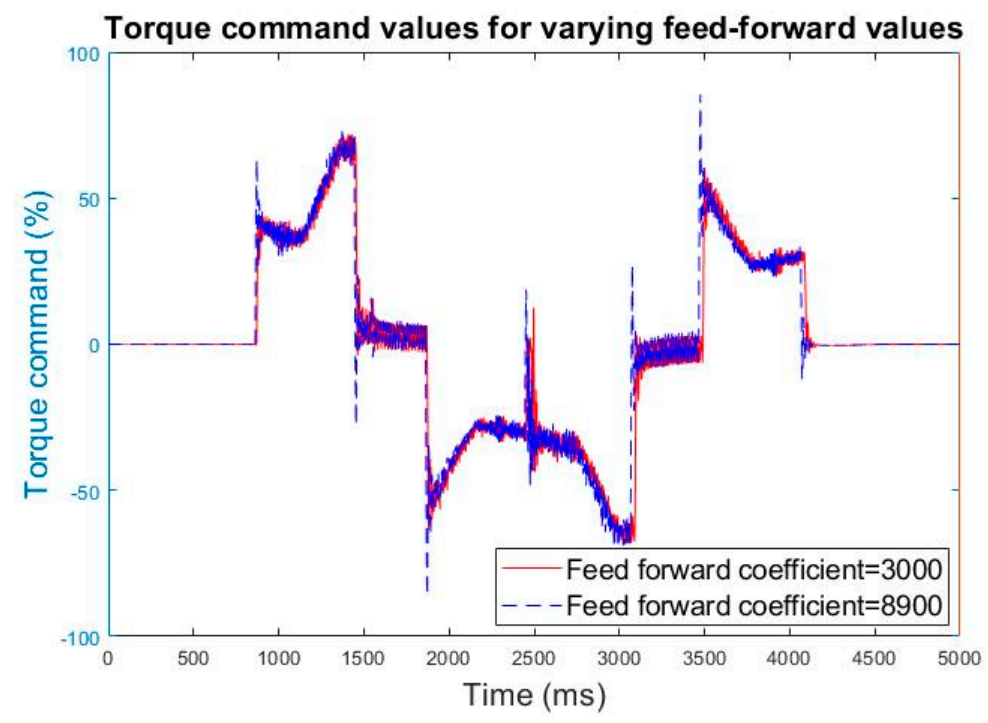

Figure 9. Torque command values for varying feedforward coefficients.

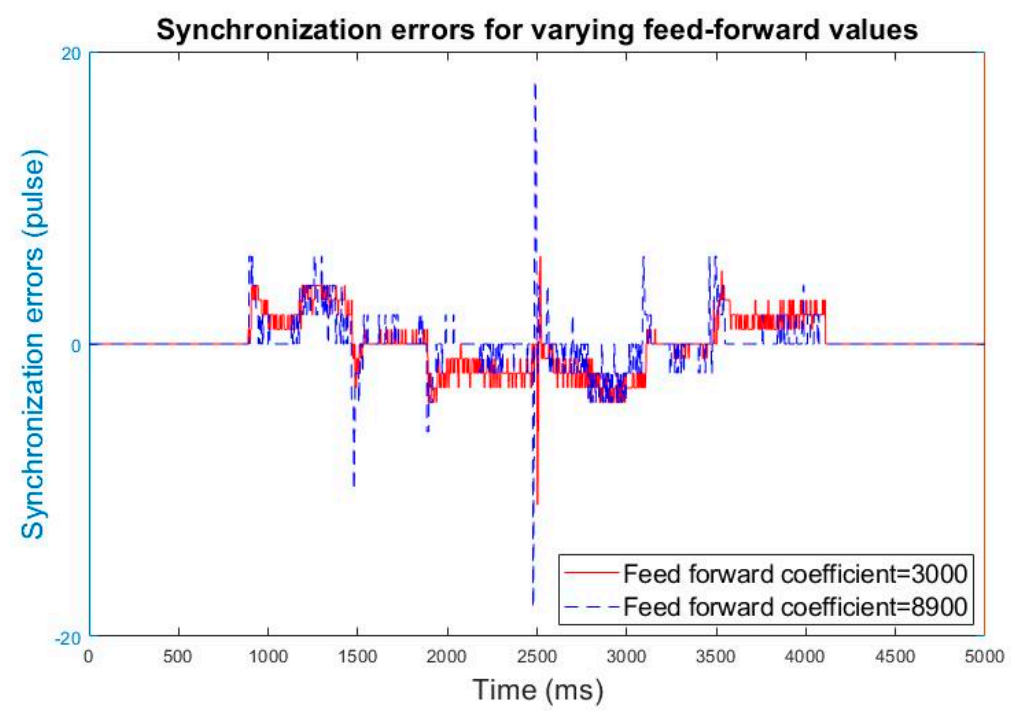

Figure 10. Synchronization errors for varying advanced feedforward coefficients.

Author Contributions: Formal analysis, P.-Y.C. and P.-Y.Y.; funding acquisition, P.-Y.Y. and J.-H.C.; methodology, S.-H.C. and J.-H.C.; software, P.-Y.C. and P.-Y.Y.; supervision, S.-H.C. and J.-H.C.; validation, P.-Y.C. and P.-Y.Y.; writing—original draft, P.-Y.C. and P.-Y.Y.; writing—review and editing, S.-H.C. and J.-H.C. All authors have read and agreed to the published version of the manuscript.

Funding: This research was funded in part by the Ministry of Science and Technology, Taiwan, R.O.C., grant numbers MOST 107-2221-E-992-086-MY3, and MOST 109-2222-E-035-002. And the APC was funded by MOST 107-2221-E-992-086-MY3.

Institutional Review Board Statement: Not applicable.

Informed Consent Statement: Not applicable.

Data Availability Statement: The authors collected the data by themselves using the proposed method for this article.

Conflicts of Interest: The authors declare no conflict of interest. 


\section{References}

1. Lee, K.; Ibaraki, S.; Matsubara, A.; Kakino, Y.; Suzuki, Y.; Arai, S.; Braasch, J. A servo parameter tuning method for high-speed NC machine tools based on contouring error measurement. Laser Metrol. Mach. Perform. VI 2003, 44, 181-192.

2. Yeh, S.S.; Lee, J.I. Optimal tuning of control gains for rigid tapping processes using a learning automata methodology. In Proceedings of the IEEE Congress on Evolutionary Computation (CEC), Sendai, Japan, 25-28 May 2015; pp. 3248-3255.

3. Yeh, C.F.; Huang, W.S.; Kuo, C.H.; Hsu, P.L. Design and applications of the synchronized motion controller for tapping processes. In Proceedings of the 2012 XXth International Conference on Electrical Machines, Marseille, France, 2-5 September 2012; pp. 143-149.

4. Lu, J.; Zou, H.; Shen, L.; Zou, X. Application of adaptive fuzzy-pid control in servo spindle rigid tapping. Adv. Mater. Res. 2011, 301-303, 1477-1481. [CrossRef]

5. Sencer, B.; Ishizaki, K.; Shamoto, E. Cross coupling controller for accurate motion synchronization of dual servo systems. Int. J. Autom. Technol. 2013, 7, 514-522.

6. Biris, C.; Breaz, R.; Girjob, C.; Chicea, A. Researches regarding optimising the contouring precision of CNC laser cutting machines. Appl. Mech. Mater. 2014, 555, 580-585. [CrossRef]

7. Chen, S.L.; Pan, C.I.; Chou, C.Y. Reduction of synchronous errors in rigid tapping by iterative learning control. In Proceedings of the 2012 IEEE/ASME International Conference on Advanced Intelligent Mechatronics (AIM), Kaohsiung, Taiwan, 11-14 July 2012; pp. 467-471.

8. Andrearczyk, A.; Bagiński, P.; Klonowicz, P. Numerical and experimental investigations of a turbocharger with a compressor wheel made of additively manufactured plastic. Int. J. Mech. Sci. 2020, 178, 105613. [CrossRef]

9. Isaias Hernandez-Carrillo, I.; Wood, C.J.; Liu, H. Advanced materials for the impeller in an ORC radial microturbine. Energy Procedia 2017, 129, 1047-1054. [CrossRef]

10. Żywica, G.; Bagiński, P.; Andrearczyk, A. A new method of manufacturing a foil bearing using tools made by the rapid prototyping technology. CIRP J. Manuf. Sci. Technol. 2020, 31, 514-524. [CrossRef]

11. Bekker, A.C.M.; Verlinden, J.C. Life cycle assessment of wire + arc additive manufacturing compared to green sand casting and CNC milling in stainless steel. J. Clean. Prod. 2018, 177, 438-447. [CrossRef]

12. Andrearczyk, A.; Konieczny, B.; Sokołowski, J. Additively Manufactured Parts Made of a Polymer Material Used for the Experimental Verification of a Component of a High-Speed Machine with an Optimised Geometry-Preliminary Research. Polymers 2020, 13, 137. [CrossRef] [PubMed]

13. Yamazaki, T. Development of A Hybrid Multi-tasking Machine Tool: Integration of Additive Manufacturing Technology with CNC Machining. Procedia CIRP 2016, 42, 81-86. [CrossRef]

14. Chen, C.S.; Sun, Y.T.A. Intelligent Computer-aided Process Planning of Multi-axis CNC Tapping Machine. IEEE Access 2017, 5, 2913-2920. [CrossRef]

15. Ma, Y.C.; Wan, M.; Yang, Y.; Zhang, W.H. Dynamics of tapping process. Int. J. Mach. Tools Manuf. 2019, 140, 34-47. [CrossRef]

16. Ning, J.; Zhou, Y.; Fang, K.T. Discrepancy for uniform design of experiments with mixtures. J. Stat. Plan. Inference 2011, 141, 1487-1496. [CrossRef]

17. Wang, Y.; Fang, K.T. A note on uniform distribution and experimental design. Chin. Sci. Bull. 1981, 26, 485-489.

18. Fang, K.T. Uniform Design and Uniform Layout; Science Press: Beijing, China, 1994.

19. Tsao, H.; Lee, L. Uniform layout implement on MATLAB. Stat. Decis. 2008, 2008, 144-146.

20. Jebaseeli, E.A.E. Monitoring the thermal behavior of induction motor using regression technique. In Proceedings of the 2017 Innovations in Power and Advanced Computing Technologies (i-PACT), Vellore, India, 21-22 April 2017; pp. 1-4.

21. Yang, Y. Prediction and analysis of aero-material consumption based on multivariate linear regression model. In Proceedings of the 2018 IEEE 3rd International Conference on Cloud Computing and Big Data Analysis (ICCCBDA), Chengdu, China, 9-12 March 2018; pp. 628-632.

22. Pal, M.; Bharati, P. Applications of Regression Techniques; Springer: Singapore, 2019.

23. Olive, D. Linear Regression; Springer: New York, NY, USA, 2017.

24. Yang, P.-Y.; Chou, F.-I.; Tsai, J.-T.; Chou, J.-H. Adaptive-Uniform-Experimental-Design-Based Fractional-Order Particle Swarm Optimizer with Non-Linear Time-Varying Evolution. Appl. Sci. 2019, 9, 5537. [CrossRef]

25. Couceiro, M.; Ghamisi, P. Fractional Order Darwinian Particle Swarm Optimization; Springer: London, UK, 2016.

26. Guo, T.; Lan, J.L.; Li, Y.E.; Chen, S.W. Adaptive fractional-order Darwinian particle swarm optimization algorithm. J. Commun. 2014, 35, 130-140.

27. Solteiro Pires, E.J.; Tenreiro Machado, J.A.; Moura Oliveira, P.B.d. Fractional particle swarm optimization. In Mathematical Methods in Engineering; Fonseca, N.M., Tenreiro Machado, J.A., Eds.; Springer: London, UK, 2014; pp. 47-56.

28. Gao, Z.; Wei, J.; Liang, C.; Yan, M. Fractional-Order Particle Swarm Optimization. In Proceedings of the 26th Chinese Control and Decision Conference (CCDC), Changsha, China, 3 May-2 June 2014.

29. Hsu, C.C.; Yeh, S.S.; Lee, J.I. Effect analysis and optimal combination of cutting conditions on the cutting torque of tapping processes using Taguchi methods. In Proceedings of the 2016 IEEE International Conference on Automation Science and Engineering (CASE), Fort Worth, TX, USA, 21-25 August 2016; pp. 1215-1218.

30. Tsai, J.-T.; Chou, J.-H.; Liu, T.-K. Optimal design of digital IIR filters by using hybrid Taguchi genetic algorithm. IEEE Trans. Ind. Electron. 2006, 53, 867-879. [CrossRef] 
31. Huang, W.-T.; Lee, T.-Y.; Chou, J.-H. Investigating Multiple Quality Objectives for Surface Roughness and Dimensional Accuracy of Carbon Steel Manufactured by Turn-Mill Multitasking Machining. In Proceedings of the 2018 IEEE International Conference on Advanced Manufacturing (ICAM), Yunlin, Taiwan, 16-18 November 2018; pp. 134-137.

32. Taguchi, G.; Chowdhury, S.; Taguchi, S. Robust Engineering; McGraw-Hill: New York, NY, USA, 2000.

33. Do, T.V.; Vu, N.C.; Nguyen, Q.M. Optimization of cooling conditions and cutting parameters during hard milling of AISI H13 steel by using Taguchi method. In Proceedings of the 2018 IEEE International Conference on Advanced Manufacturing (ICAM), Yunlin, Taiwan, 23-25 November 2018; pp. 396-398.

34. Weng, W.-C.; Yang, F.; Elsherbeni, A. Electromagnetics and Antenna Optimization using Taguchi's Method. Synth. Lect. Comput. Electromagn. 2007, 2, 1-94. [CrossRef]

35. Luis-Ruiz, J.M.d.; Sedano-Cibrián, J.; Pereda-García, R.; Pérez-Álvarez, R.; Malagón-Picón, B. Optimization of Photogrammetric Flights with UAVs for the Metric Virtualization of Archaeological Sites. Application to Juliobriga (Cantabria, Spain). Appl. Sci. 2021, 11, 1204. [CrossRef]

36. Fernández, D.; Rodríguez-Prieto, A.; Camacho, A.M. Effect of Process Parameters and Definition of Favorable Conditions in Multi-Material Extrusion of Bimetallic AZ31B-Ti6A14V Billets. Appl. Sci. 2020, 10, 8048. [CrossRef]

37. Hutchison, G.; Zahawi, B.; Giaouris, D.; Harmer, K.; Stedall, B. Parameter estimation of synchronous machines using particle swarm optimization. In Proceedings of the 2010 IEEE 11th International Conference on Probabilistic Methods Applied to Power Systems, Singapore, 14-17 June 2010; pp. 348-351.

38. Bhattacharyya, S.; Banerjee, P.; Dutta, P.; Majumdar, D. Handbook of Research on Advanced Hybrid Intelligent Techniques and Applications. Advances in Computational Intelligence and Robotics (ACIR) Book Series; IGI Global: Hershey, PA, USA, 2015.

39. Qin, B.; Yang, Y.; Liu, Y.; Wang, J. Improved particle swarm optimized fuzzy neural network based fault diagnosis for computer numerical control machine. In Proceedings of the 2015 IEEE International Conference on Mechatronics and Automation (ICMA), Beijing, China, 2-5 August 2015; pp. 1442-1447.

40. Zhu, G.-Y.; Zhang, W.-B. Drilling path optimization by the particle swarm optimization algorithm with global convergence characteristics. Int. J. Prod. Res. 2008, 46, 2299-2311. [CrossRef]

41. Chopard, B.; Tomassini, M. An Introduction to Metaheuristics for Optimization; Springer: Berlin, Germany, 2018.

42. Ali, M.M.; Kaelo, P. Improved Particle Swarm Algorithms for Global Optimization. Appl. Math. Comput. 2008, 196, 578-593. [CrossRef]

43. Chen, X.; Li, Y. On Convergence and Parameter Selection of an Improved Particle Swarm Optimization. Int. J. Control Autom. Syst. 2008, 6, 559-570.

44. Tsai, H.-C.; Tyan, Y.-Y.; Wu, Y.-W.; Lin, Y.H. Isolated Particle Swarm Optimization with Particle Migration and Global Best Adoption. Eng. Optim. 2012, 44, 1405-1424. [CrossRef]

45. Chen, W.-N.; Zhang, J.; Lin, Y.; Chen, N.; Zhan, Z.-H.; Chung, H.-S.-H.; Li, Y.; Shi, Y.-H. Particle Swarm Optimization with an Aging Leader and Challengers. IEEE Trans. Evol. Comput. 2013, 17, 241-258. [CrossRef]

46. Lynn, N.; Suganthan, P.N. Heterogeneous Comprehensive Learning Particle Swarm Optimization with Enhanced Exploration and Exploitation. Swarm Evol. Comput. 2015, 24, 11-24. [CrossRef]

47. Chatterjee, A.; Siarry, P. Nonlinear Inertia Weight Variation for Dynamic Adaptation in Particle Swarm Optimization. Comput. Oper. Res. 2006, 33, 859-871. [CrossRef]

48. Yang, X.; Yuan, J.; Yuan, J. A Modified Particle Swarm Optimizer with Dynamic Adaptation. Appl. Math. Comput. 2007, 189, 1205-1213. [CrossRef]

49. Ko, C.-N.; Chang, Y.-P.; Wu, C.-J. An Orthogonal-Array-based Particle Swarm Optimizer with Nonlinear Time-Varying Evolution. Appl. Math. Comput. 2007, 191, 272-279. [CrossRef]

50. Tsai, J.-T.; Chou, P.-Y.; Chou, J.-H. Color Filter Polishing Optimization Using ANFIS with Sliding-Level Particle Swarm Optimizer. IEEE Trans. Syst. Man Cybern. Syst. 2020, 50, 1193-1207. [CrossRef]

51. Xin, B.; Chen, J. A Survey and Taxonomy on Hybrid Algorithms based on Particle Swarm Optimization and Differential Evolution. J. Syst. Sci. Math. Sci. 2011, 31, 1130-1150.

52. Noel, M.M. A New Gradient Based Particle Swarm Optimization Algorithm for Accurate Computation of Global Minimum. Appl. Soft Comput. 2012, 12, 353-359. [CrossRef]

53. Sun, Y.; Zhang, L.; Gu, X. A Hybrid Co-Evolutionary Cultural Algorithm based on Particle Swarm Optimization for Solving Global Optimization Problems. Neurocomputing 2012, 98, 76-89. [CrossRef]

54. B-65264EN. Fanuc Servo Tuning Procedure Manual; Fanuc Corporation: Yamanashi, Japan, 2005.

55. B-65280EN/07. Fanuc AC Spindle Motor Alpha-i series Parameter Manual; Fanuc Corporation: Yamanashi, Japan, 2008.

56. B-65270EN/07. Fanuc AC Servo Motor Alpha-i series Parameter Manual; Fanuc Corporation: Yamanashi, Japan, 2007.

57. B-63950EN. Fanuc Series 30i/300i/300is-MODEL-A Parameter Manual; Fanuc Corporation: Yamanashi, Japan, 2004. 